\title{
VIII. Notes on the plug permeameter
}

\section{Charles V. Drysdale D.Sc.}

To cite this article: Charles V. Drysdale D.Sc. (1908) VIII. Notes on the plug permeameter , Philosophical Magazine Series 6, 16:91, 132-136, DOI: 10.1080/14786440708636494

To link to this article: http://dx.doi.org/10.1080/14786440708636494

$$
\text { 册 Published online: } 21 \text { Apr } 2009 .
$$

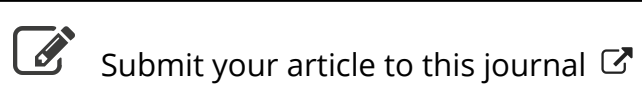

\footnotetext{
Џll Article views: 2
}

Q View related articles $₫$ 


\section{$\left[\begin{array}{ll}132 & ]\end{array}\right.$ \\ VIII. Notes on the Plug Permeameter. By Charles V. Drysdale, D.Se**}

[Plates II. \& III.]

TN 1901 the writer described a permeameter $t$, devised with the object of enabling permeability-tests to be made on castings and forgings for dynamo-work. The apparatus consisted of a special drill, which could be employed to bore a hole in the casting or forging, leaving, however, a small piece of the metal in the form of a rod or pin standing in the centre of the hole. A split iron plug, arranged to fit both the conical sides of the hole and over the pin, was employed to complete the magnetic circuit; and this plug carried a bobbin wound with magnetizing and search coils. A special portable testing set was also designed with the object of making permeability-tests by direct reading of $\mathrm{H}$ and $\mathrm{B}$.

It was noticed at the time that the magnetization-curves obtained by this method fell below those obtained by measurements on a long bar of the same material. This would naturally be attributed to a bad magnetic joint between the pin and plug; but experiments made at the time seemed to point rather to the effect being due to the reluctance of the return path at the point of entrance of the flux, due to the concentration of the lines of force at these points. This seemed probable from the fact that the readings were remarkably consistent when the plug was removed and replaced.

This hypothesis rendered it probable that there might be a more or less definite relation between the value of the true magnetizing-force $\mathrm{H}$ in the specimen, and the apparent magnetizing-force $\mathrm{H}^{\prime}=\frac{4 \pi}{10} \frac{\mathrm{C} n}{l}$; and arrangements were made to test this relation. The most perfect method was suggested by the double-yoke method of Prof. Ewing. It consisted in finding the relation of the induction density and the magnetizing current for the ordinary drilled specimen, and afterwards when the length of the specimen was doubled by drilling to a greater depth with a second drill. The increase of the magnetizing current for the same induction should give the true $\mathrm{H}$. A large number of tests were made in this manner, but proved of little value, as, although the first drilling presented no difficulties, it was found impossible to perform the second drilling accurately enough to preserve parallelism of the pin.

* Communicated by the Physical Society : read March 27, 1908.

$\uparrow$ Proc Inst. Electr. Eng. vol. xxxi. p. 283. 
Recourse was therefore had to the more simple device of obtaining some specimens of cast and wrought iron and steel, in the form of rings; testing them by the ordinary ring method, and afterwards cutting them up and drilling, for tests by the plug. Rings of this lind were made for us by Messrs. G. Wailes of Euston Road, and were of ordinary cast iron (O.C.I.), special cast iron (S.C.I.), wrought iron (W.I.), and mild steel (M.S.). ' 'Two rings of each material were tested, and each ring was cut into four quadrants. Each of these quadrants was drilled in both ends, so that eight drillings were made in each ring. Readings of $B$ were then made with the plug method, at nominal values of $H$ of 30 and 100 on the eight drillings, and the drilling selected for final test, the readings on which corresponded to the mean of the eight. It may be mentioned that the whole of the 64 drillings on the eight rings were made with the same drill, which was none the worse after. None of the drillings

Fig. 1.

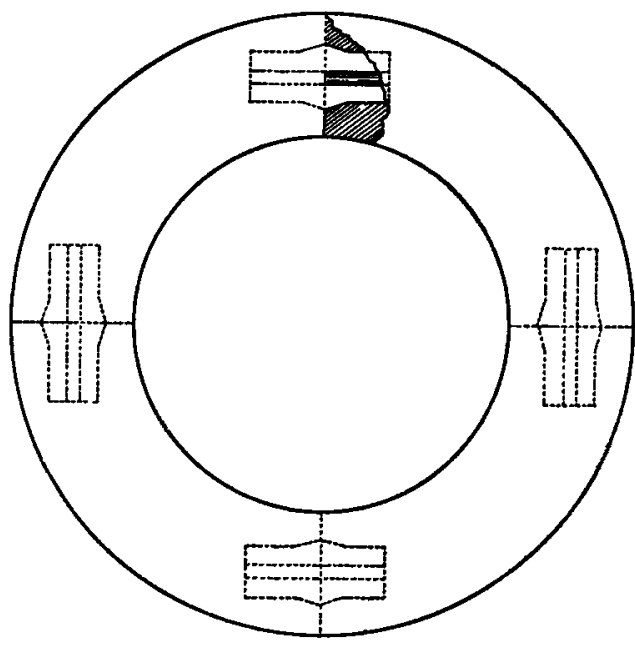

gave a bad fit with the plug. Fig. 1 shows the form and mode of cutting and drilling the ring, which was 5 in. external diameter and 1 in. square in section; while Table $I$. shows an example of the readings on the various drillings of one ring, and the amount of variation usually found. It should be specially noted that these variations are not apparently due to variation in the fit of the plug, but rather to actual differences in the magnetic quality of the iron. 
Table I.

Readings on Wrought Iron Ring.

\begin{tabular}{|c|c|c|c|}
\hline $\begin{array}{l}\text { Hole } \\
\text { No. }\end{array}$ & Fit. & $\underset{\mathrm{B}}{\mathrm{H}=30}$ & $\begin{array}{c}\mathrm{H}=100 \\
\mathrm{~B} .\end{array}$ \\
\hline $\begin{array}{ll}1 & \ldots . . \\
2 & \ldots \ldots . \\
3 & \ldots \ldots . \\
4 & \ldots \ldots \\
5 & \ldots \ldots \\
6 & \ldots \ldots \\
7 & \ldots \ldots . \\
8 & \ldots \ldots \\
& \ldots \ldots\end{array}$ & $\begin{array}{c}\text { Fair. } \\
\text { Moderate. } \\
\text { Good. } \\
\text { Good. } \\
\text { Fair. } \\
\text { Good. } \\
\text { Good. } \\
\text { Fair. }\end{array}$ & $\begin{array}{l}13,140 \\
12,880 \\
12,400 \\
12,040 \\
11,730 \\
12,930 \\
11,000 \\
11,670\end{array}$ & $\begin{array}{l}15,600 \\
15,820 \\
15,130 \\
14,550 \\
14,550 \\
15,080 \\
14,190 \\
14,550\end{array}$ \\
\hline \multicolumn{2}{|c|}{1 (Check-reading) ...... } & $\ldots \ldots$ & 15,600 \\
\hline \multicolumn{2}{|c|}{ Mean $\ldots \ldots \ldots \ldots \ldots \ldots$} & 12,250 & 14,900 \\
\hline
\end{tabular}

Figs. 2-9, Pl. II., show magnetization-curves taken on the ring and by the plug on the mean drilling for each specimen. It will be noted that the curve obtained by the plug lies below that for the ring in every case; but there is no evidence to show that this is due to an air-gap. If such a gap were present, of approximately equal amount in each of the specimens, the shearing-over of the curves of the wroughtiron and mild-steel specimens would be much more marked in comparison to those of the cast-iron specimens, owing to the much greater permeability and induction-density in the former.

Table II. is obtained from the curves by finding the value of $\mathrm{H}^{\prime}$, the nominal magnetizing force in the case of the plugtest, for each value of $\mathrm{H}$ from the ring-test, for a given induction-density; and fig. 10, Pl. II., gives curves showing the relation of $\dot{H}^{\prime}$ to $\mathrm{H}$ for each of the materials and for the mean of all. It will be observed that although there are considerable differences between the values in the various columns, they appear to have no relation to the permeability of the specimen, and must therefore be regarded as accidental. In fact, the difference between $\mathrm{H}$ and $\mathrm{H}^{\prime}$ is greater in the case of the special cast-iron than for either the wroughtiron or mild-steel specimens, which is exactly contrary to the effect which would be produced by an air-gap. The difference must consequently be attributed to the shortness of the specimen; and the results therefore may have some general value in indicating the amount of the end effect in the case of yokepermeameters, in which the specimen is only five diameters long. 
on the Plug Permeameter.

TABLE II.

Relation of $\mathrm{H}$ to $\mathrm{H}^{\prime}$.

\begin{tabular}{|c|c|c|c|c|c|}
\hline H. & $\begin{array}{l}\text { Mean } H^{\prime} \\
\text { for O.C.I. }\end{array}$ & $\begin{array}{l}\text { Mean } H^{\prime} \\
\text { for S.C.I. }\end{array}$ & $\begin{array}{l}\text { Mean } H^{\prime} \\
\text { for W.I. }\end{array}$ & $\begin{array}{l}\text { Mean } H^{\prime} \\
\text { for M.S. }\end{array}$ & Mean. \\
\hline 0 & 0 & 0 & 0 & 0 & 0 \\
\hline $5 \ldots$ & $8 \cdot 5$ & $9 \cdot 7$ & $8 \cdot 5$ & $8 \cdot 0$ & $8 \cdot 7$ \\
\hline $10 \ldots$. & $17 \cdot 2$ & $19 \cdot 2$ & $18 \cdot 75$ & $18 \cdot 5$ & $18 \cdot 4$ \\
\hline $15 \ldots$. & $26 \cdot 2$ & $29 \cdot 4$ & $28 \cdot 2$ & $29 \cdot 0$ & $28 \cdot \overline{2}$ \\
\hline $20 \ldots$. & $34 \cdot 0$ & $39 \cdot 0$ & $35 \cdot 7$ & $37 \cdot 7$ & $36 \cdot 6$ \\
\hline $25 \ldots$. & $42 \cdot 2$ & $47 \cdot 7$ & $42 \cdot 2$ & $46 \cdot 5$ & $44 \cdot 7$ \\
\hline $30 \ldots .$. & $49 \cdot 5$ & 56.0 & $48 \cdot 0$ & $54 \cdot 2$ & $51 \cdot 5$ \\
\hline $35 \quad \ldots \ldots$ & $57 \cdot 0$ & $65 \cdot 25$ & $54 \cdot 0$ & $61 \cdot 0$ & $59 \cdot 3$ \\
\hline $40 \ldots .$. & $63 \cdot 5$ & 73.75 & $60 \cdot 5$ & $66 \cdot 5$ & 660 \\
\hline $45 \ldots .$. & 69.5 & $81 \cdot 75$ & $64 \cdot 5$ & $72 \cdot 2$ & $71 \cdot 9$ \\
\hline $50 \ldots$. & $76 \cdot 5$ & $90 \cdot 75$ & $69 \cdot 7$ & $77 \cdot 5$ & 78.5 \\
\hline $55 \ldots \ldots$ & $83 \cdot 5$ & 98.25 & $75 \cdot 0$ & $82 \cdot 0$ & 84.7 \\
\hline $60 \ldots$. & 90.0 & $106^{\circ} 0$ & 79.5 & 88.5 & $91 \cdot 0$ \\
\hline $65 \ldots .$. & $96 \cdot 5$ & $114: 0$ & $83 \cdot 7$ & $93 \cdot 2$ & 969 \\
\hline $70 \ldots .$. & 103.0 & 321.5 & $89 \cdot 0$ & $97 \cdot 5$ & $102 \cdot 8$ \\
\hline $75 \ldots$. & $109 \cdot 2$ & $129 \cdot 0$ & $94 \cdot 2$ & 1022 & $108 \cdot 6$ \\
\hline $80 \ldots .$. & 115.0 & 1357 & 99.0 & $108 \cdot 5$ & $114 \cdot 6$ \\
\hline
\end{tabular}

In order to show the result of correcting the indications of the instrument, the curves figs. 2-9 have points marked by crosses, in which the readings of the plug-permeameter are shifted backwards along the $\mathrm{H}$ axis by amounts corresponding to the mean curve in fig. 10 . The agreement with the ringtests then becomes fairly good. Fig. 11, Pl. III., shows readings taken by one of the portable testing sets, in which the $\mathrm{H}$ scale has been marked off in this way. The curves are those given by the ring method, while the points are taken by the testing set. The agreement is as good as in most of the recognized permeameters.

Fig.12, Pl. III., shows two curves taken by the plug permeameter : one on a cast-steel pole-piece for a large generator, which was sent us by the dynamo-builders under the impression that it was of poor magnetic quality. The test shows the permeability to be very good. The other curve is for another specimen of steel, and indicates the remarkable variations of quality which are found in practice.

It should be mentioned that when the plug used in these tests was replaced by a second one, the results agreed within an accuracy of $1 \frac{1}{2}$ per cent.

The general conclusion to be drawn from these experiments is that the plug permeameter, in reasonably careful hands. gives as good results as any other method of iron testing, so far as permeability tests are concerned. In a recent paper 


\section{Dr. Drysdale on the Use of Shunts and Transformers}

by Mr. Murdoch* this permeameter was criticized as employing a very small specimen; but this is precisely what has been aimed at in its design. It appears to be of great importance that permeameters for castings or forgings should be capable of being employed on the bulk of the metal itself, without extra machined specimens, and up to the present no other instrument has been devised which meets this requirement.

The writer's hearty thanks are due to Mr. A. C. Jolley for the considerable amount of work involved in carrying out the tests. Mr. C. M. Dowse has also rendered considerable assistance in the later tests.

IX. The Use of Shunts and Transformers with Alternate Current Measuring Instruments. By Charles V. Drysdale, D.Sc. $\dagger^{\prime}$

[Plate IV.]

$7 \mathrm{HE}$ growing demand for instruments for alternate-current measurement, of considerable range and accuracy, has called attention to some of the difficulties attending their production, especially to their limited range. As alternatecurrent instruments measure the root-nean-square values of the P.D. or current, it necessarily follows that the deflecting torque falls very rapidly as the P.D. or current is decreased, For most commercial instruments, it may be taken that a tenfold range of torque is the utmost possible for accurate reading, so that when the deflexion is proportional to the torque the range of an A.C. instrument can only be of the order of 3 to 1 except by the employment of double coils or auxiliary devices. The auxiliary devices which may be employed are transformers for electromagnetic ammeters, voltmeters, and wattmeters; shunts for ammeters and wattmeters, series resistances for electromagnetic voltmeters, and condensers and split resistances for electromagnetic voltmeters. Of these, the use of shunts and transformers may give rise to serious errors, and it is proposed here to investigate the amount of these errors and the conditions for their elimination.

In dealing with any shunting or transforming device we must bear in mind that it may cause errors in two ways:- $(a)$ by the multiplying power of the shunt or the ratio of the transformer being affected by frequency, \&c.; and (b) by a phase displacement being introduced between the current or P.D.

* Electrician, Fol. lx. p. 245.

† Communicated by the Physical Society : read March 27, 1908. 


Fra. 12.
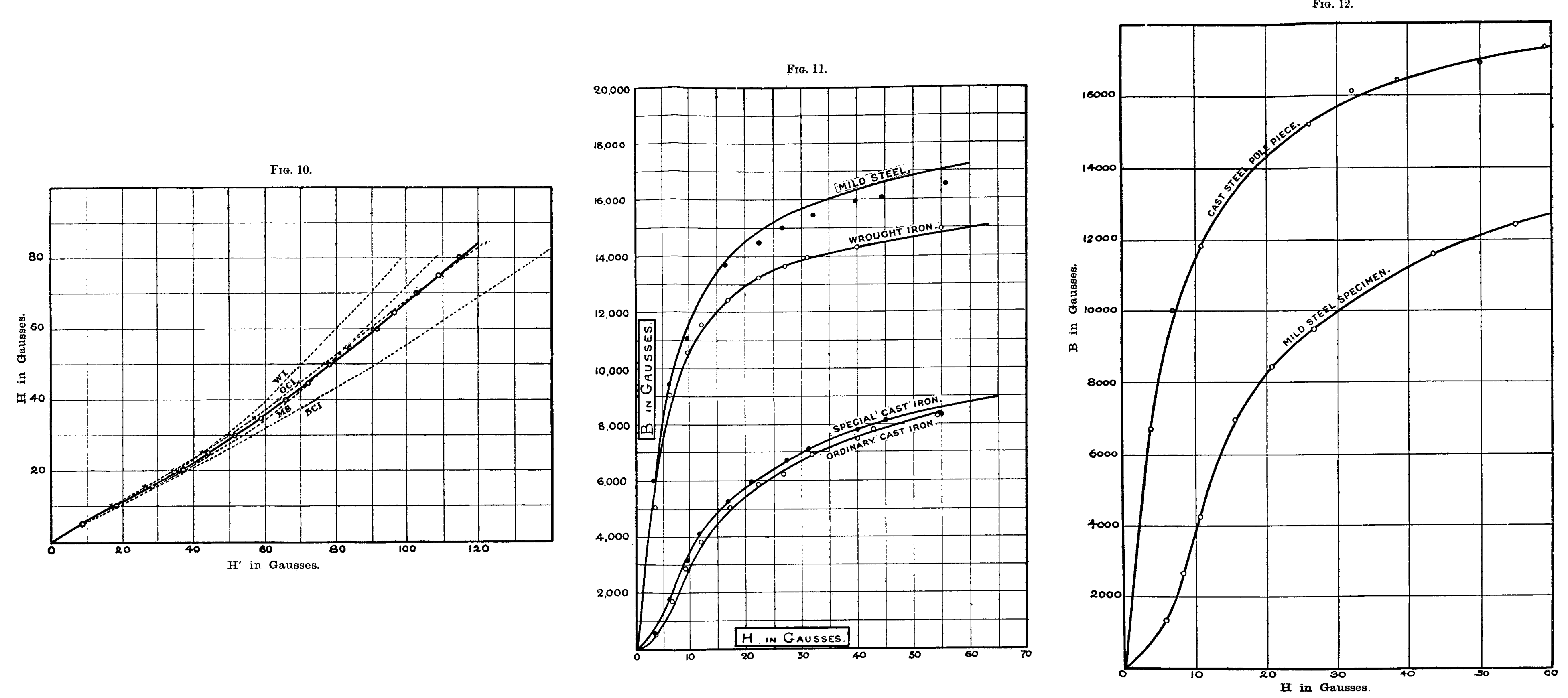